\title{
Deformation of Material in Punching of Slanted Fine Hole in SUS304 Sheets with Fine-Grained Microstructure*1
}

\author{
Masahito Katoh ${ }^{1, * 2}$, Tomomi Shiratori ${ }^{2}$, Yohei Suzuki ${ }^{2}$, Shizuka Nakano ${ }^{1}$ and Takafumi Komatsu ${ }^{2}$ \\ ${ }^{1}$ Advanced Manufacturing Research Institute, National Institute of Advanced Industrial Science and Technology, \\ Tsukuba 305-8564, Japan \\ ${ }^{2}$ Komatsuseiki kosakusho. Co., ltd., Suwa 392-0012, Japan
}

It is necessary to understand behaviors of the material in worked sheet to reduce troubles of punch fracturing in the punching of slanted fine holes in austenitic stainless-steel SUS304 sheets. The behavior of the material is estimated as the follows by the map of Vickers hardness in the cross-section of worked sheet. The material flow changes the complexity of what as a result of the influence of work hardening or transformation to strain-induced martensite. Then, the direction and magnitude of the pressure applied to the punch also change such inn a complex manner. However, the worked material almost flows into the die hole. Then, the punch is carried into the hole by this material flow. [doi:10.2320/matertrans.P-M2015834]

(Received February 25, 2015; Accepted September 28, 2015; Published December 25, 2015)

Keywords: punching, micro forming, stainless steel, deformation behavior, fine grain, slanted hole

\section{Introduction}

Orifice plates in fuel injection of automobile engines have been mass-produced by a press-punching process. ${ }^{1}$ Holes on the orifice plates have been narrowed for the purpose of achieving fuel efficiency. In the punching process of metal sheets, the stress to punch is inversely proportional to the diameter of holes being punched, while sheet-thickness remaining constant. ${ }^{2)}$ Thus, the stress to punch increases as the diameter of punched hole decreases. Furthermore, as the punch narrows it loses its rigidity and becomes susceptible to breakage.

On the other hand, by the external forces, the punch undergoes a deformation which changes the complexity of the slanted punching process ${ }^{3,4)}$ and makes the job more difficult.

The industry's process for manufacturing of orifice plates for automobile also involves narrow and slanted punching onto thin sheets of stainless steel. In this case, quite a bit of difficulties are encountered that result from fractured punches that are found to occur during their use.

In order to minimize these troubles, it is necessary to fully understand the flow of the working materials in the punching process. There has been a report on the dimensions around the fine holes in slanted thin sheet of punched metal, ${ }^{5)}$ but no such reports have been presented on the flow in a slanted punching process. In addition, the numerical simulation that addresses the evolution of heat generation in a very short time of a few milliseconds has also not been validated.

With these backgrounds, we proceeded to understand the material flow by metallographic observation of cross-section, and mapping of micro-hardness, in the punching of slanted fine hole.

\section{Experimental Procedure}

The material, used for the processing here, was a thin sheet

\footnotetext{
${ }^{* 1}$ This Paper was Originally Published in Japanese in J. JSTP 55 (2014) 223-227.

${ }^{* 2}$ Corresponding author, E-mail: Katoh.m@aist.go.jp
}

Table 1 Chemical composition of presented SUS304 sheet (mass\%).

\begin{tabular}{cccccccc}
\hline $\mathrm{C}$ & $\mathrm{Si}$ & $\mathrm{Mn}$ & $\mathrm{P}$ & $\mathrm{S}$ & $\mathrm{Ni}$ & $\mathrm{Cr}$ & $\mathrm{Fe}$ \\
\hline 0.06 & 0.40 & 1.09 & 0.030 & 0.004 & 8.03 & 18.02 & Bal. \\
\hline
\end{tabular}

of austenitic stainless steel SUS304 manufactured by Tokushu Kinzoku EXCEL Co. Ltd. The width of sheet was $20 \mathrm{~mm}$ and its thickness was $100 \mu \mathrm{m}$. The chemical composition of the sheet is shown in Table 1. The material was produced by a thermo-mechanical treatment of metal that employed a reverse transformation of strain induced martensite by hard cold working. ${ }^{6)}$ The optical microstructure of the cross-section of the sheet which was polished and etched by Villela liquid (nitric acid: hydrochloric acid: glycerin $=1: 2: 3$ ), is shown in Fig. 1 . The diameter of the grains in this figure is the order of 2 to $3 \mu \mathrm{m}$; and the layered structure was nearly parallel to the surface of sheet as appeared by a deep etching.

The construction of experiment die set is shown in Fig. 2. The device comprised a punch, a die, and a stripper made by cemented carbide. The outer diameter of the punch was $94 \mu \mathrm{m}$, and the inside diameter of the hole of die was $100 \mu \mathrm{m}$. The angle between the punch (or the hole), and the processing sheet was $60^{\circ}$. As follows, we call left to 'inside' and right to 'outside', because they are near to punch inside (or outside) to the sheet. Plant oil was applied to both sides of the sheet as a lubricant. For the sake of comparison an experiment with straight punching of the sheet with a same punch-diameter (as in the primary experiment) was conducted.

In the experiment being described here the punch was stopped at a half-depth to punching. Using the procedure, several half-punched sheets with several different depths were prepared for the next set of experiments with halfpunched samples. Next, they were molded in cold-curing resin, and then, they were grinded to the center of the punched dent (or hole) by Emery paper followed by a final polishing. After that, the polished surfaces were etched by 


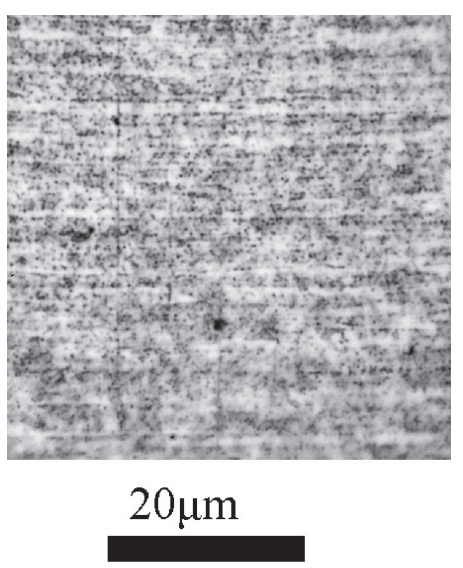

Fig. 1 Optical micro-structures of presented SUS304 sheet.

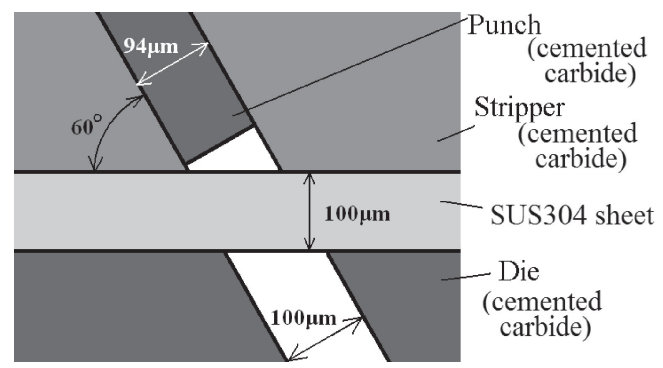

Fig. 2 Outline of the die set.

Villela liquid, and then the photographs of the optical microstructure were taken.

Vickers hardness was measured at $10 \mu \mathrm{m}$ pitch by a hardness tester (type MMT-X3 manufactured by Matsuzawa Co. Ltd.). Measuring conditions of the hardness tester were $49.03 \mathrm{mN}(=5 \mathrm{gf})$ and $10 \mathrm{~s}$.

\section{Experimental Results and Discussion}

Figures 3 and 4 are the optical micro-structures of the cross-sections of the straight and slant punched samples. Because by the samples being too small, their surface became curved by polishing, and that resulted in focus variations at different positions when looking at their high magnification photos. Then, as for the photographs, it was composed as a mosaic.

The process of slanted punching is addressed in the next three steps: '1st: from the punch contacts to work sheet to the bottom surface penerate into it; ' 2 nd: from the previous process to creation of fractured surface; ' $3 \mathrm{rd}$ : from the fractured surface starts to its end.

Photographs in Fig. 4 (at slanted punching test) are the end of the 1st step. And just before the end of the 2nd step, punched sheet and punched piece, are shown from the top. The punched piece was collected after few punched tests; then the combination of the punched sheets and the pieces may not be belonging to the same sample. Even the combinations at straight punching are similar.

The outside of the extruded material was formed to be straight and vertical to the worked sheet. The structure was not formed at punching process, but was formed at sample

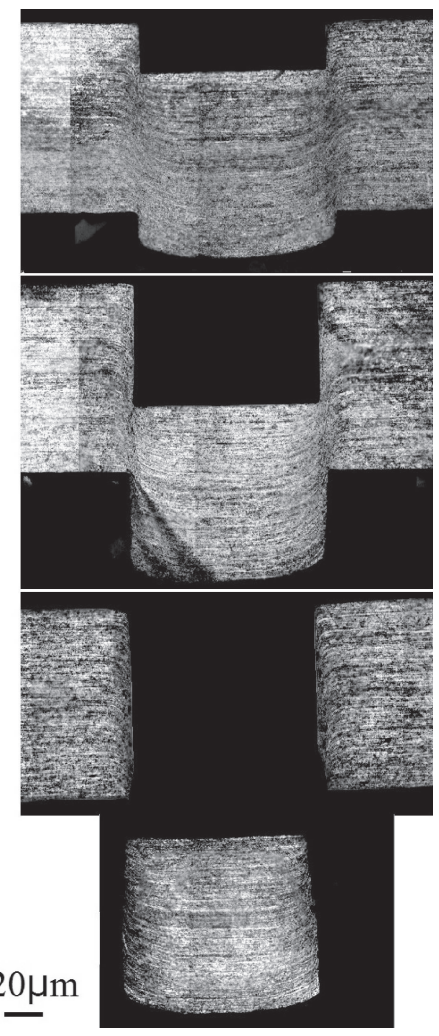

Fig. 3 Optical micro-structures on straight punching process.

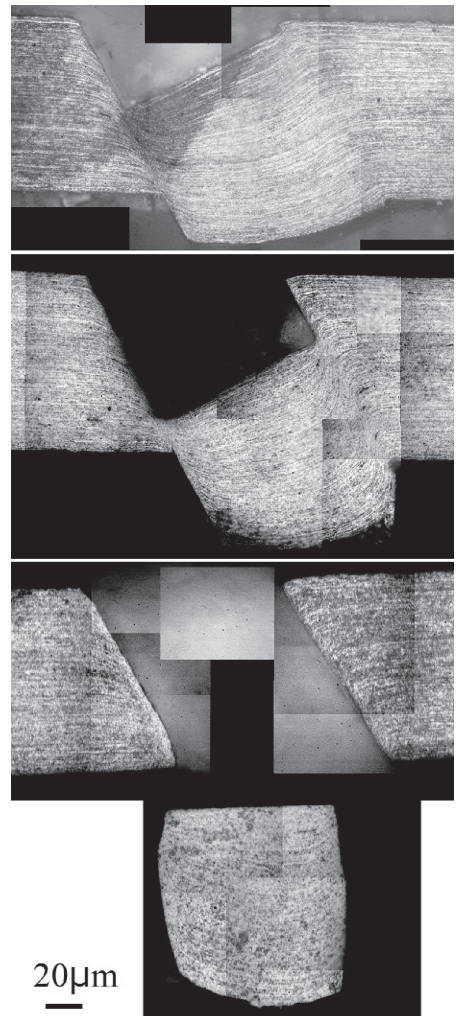

Fig. 4 Optical micro-structures on slanted punching process.

collection, because the handling was different to normal operation. Then the shape is no longer a true shape on the way of its punching process.

The presented samples have layered structures in the optical micro-structure of cross-section. It is now possible to 


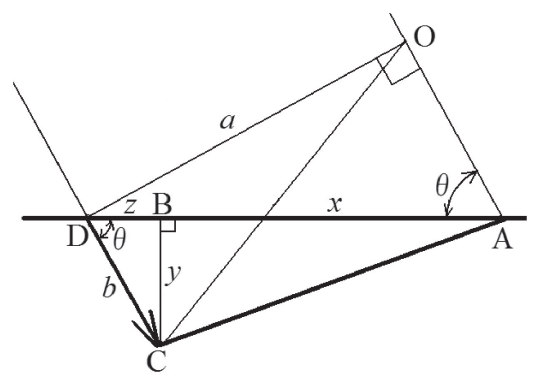

Fig. 5 Conversion the inclination of layer structure to shearing strain.

understand the strain distribution in the samples in order to observe the deformation of the structure. At straight punching, the layer structure is kept horizontal at any place other than at the shearing part, as is shown in Fig. 3.

On the other hand, the layered structure with a gradient of $30^{\circ}$ is parallel to the bottom surface of the punch at the punched area that is still at the end of the 1st step, at the slanted punched sample. To observe the detail of the slanted punched sample, linear structures at $45^{\circ}$ to sheared edge are shown from the edges of the inside and outside of the punch, each other.

Next, we calculate the value of the strain from the gradient of the layer structure. In this calculation, we suppose that the strain is a simple strain and lies within a plane that is oriented to the direction of the punching. The gradient of the layer structure is same with strain at straight punching. On the other hand, it is necessary to convert the gradient of the structure to strain at slanted punching.

In Fig. 5, the segment $\mathrm{AD}$ is the layered structure after worked sample, which has the slope of $y / x$, and the segment $\mathrm{AD}$ is the layer structure of the presented sample which is the horizontal line. Theta $(\theta)$ is the angle between the segments $\mathrm{AC}$ and $\mathrm{AD}$. The lines $\mathrm{OA}$ and $\mathrm{DC}$ are parallel lines in the direction of punching. In this case, it is considered that the shear deformation of materials between the lines OA and DC are uniformly, and the point $\mathrm{D}$ moves to point $\mathrm{C}$ by the deformation. In this case, the shearing strain $\gamma=b / a$. Here, $a$ and $b$ are the lengths of the segments OD and DC.

$$
\begin{aligned}
b & =\frac{y}{\sin \theta}, \quad z=b \cos \theta \\
a & =(x+z) \sin \theta \\
& =(x+b \cos \theta) \\
& =x \sin \theta+y \cos \theta
\end{aligned}
$$

Here, $x, y$, and $z$ are the lengths of the segments $\mathrm{AB}, \mathrm{BD}$, and $\mathrm{BC}$. Then, the shearing strain $\gamma$ is calculated by the next formula (1).

Here, $x, y$, and $z$ are the lengths of the segments $\mathrm{AB}, \mathrm{BD}$, and $\mathrm{BC}$. Then, the shearing strain $\gamma$ is calculated by the next formula (1).

$$
\gamma=\frac{b}{a}=\frac{y}{x \sin ^{2} \theta+y \sin \theta \cos \theta}
$$

Therefore, $\gamma_{60}$ which is the shearing strain at $\theta=60^{\circ}$ is calculated by the next formula (2).

$$
\gamma_{60}=\frac{4 y}{3 x+\sqrt{3 y}}
$$

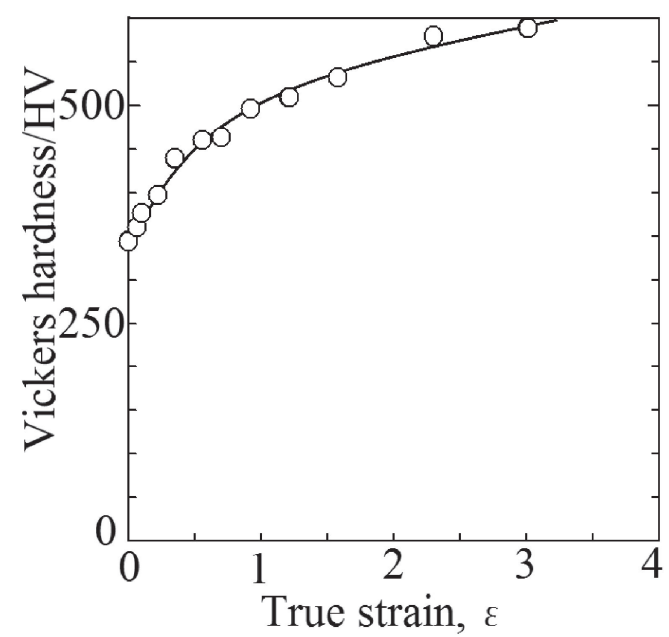

Fig. 6 Relationship of Vickers hardness and true strain of SUS304 with $3 \mu \mathrm{m}$ grain-size in cold rolling.

Then we can calculate $\gamma$ as the shearing strain from $y / x$ as the slope of the layer structure.

At the part of diagonally right down, it can be considered as the same, and the next formula (3) and (4) are introduced. They are the same formula with formula (1) and (2), but the marks of minus are added.

$$
\begin{aligned}
\gamma & =-\frac{y}{x \sin ^{2} \theta+y \sin \theta \cos \theta} \\
\gamma_{60} & =-\frac{4 y}{3 x+\sqrt{3 y}}
\end{aligned}
$$

Figure 6 shows the relationship between the Vickers hardness and true strain from a cold rolling test of SUS304 plate with grains of diameter $2 \sim 3 \mu \mathrm{m}$. In the rolling test, the initial dimensions of the test pieces are $10 \mathrm{~mm}$ of thickness, $20 \mathrm{~mm}$ of width, and $60 \mathrm{~mm}$ of length. The reductions in thickness at each rolling pass are 5 10\%. Vickers hardness was measured on the cross-section near the head of the test piece at every rolling pass. The measuring conditions were $49.03 \mathrm{mN}$ of the load and $10 \mathrm{~s}$ of the loading time. In this figure, the values of Vickers hardness are the averages of 5 times measuring at each rolling pass.

Figure 7 is the map of shearing strain, which is led from the slopes of the layer structures in Fig. 3.

Figure 8 is the map of Vickers hardness on the crosssection of the straight punched samples. Figure 9 is the map of shearing strain at the slanted punching which is calculated from the slopes of the layered structure in Fig. 4 by formulas (2) and (4); and Fig. 10 is the map of Vickers hardness in the slanted punched sample. In these figures, the color scales of each hardness and strain are fitted by the data in Fig. 6.

Regarding the maps of Figs. 9 and 10, which are the data at the slanted punching, they have a similar distribution. On the other hand, although the relative distribution is similar, the absolute value is different at straight punching as shown in Figs. 7 and 8. In straight punching, the data of the hardness are lower than the hardness by rolling test in Fig. 6.

As it is well known, that because of the forming of straininduced martensite, the behavior of the working-hardening 

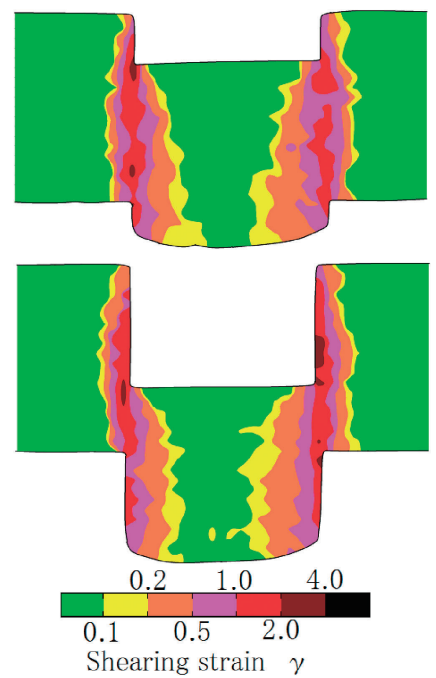

Fig. 7 Map of shearing strain in straight punching process.
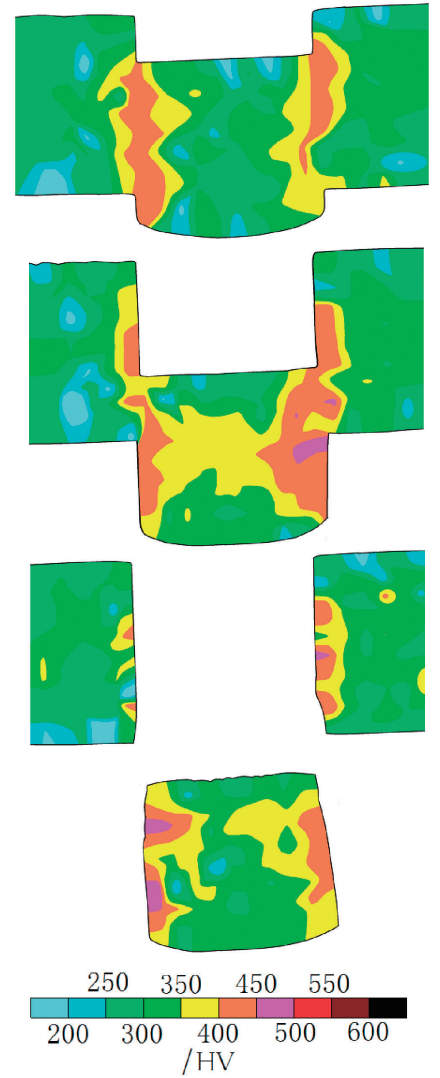

Fig. 8 Map of Vickers hardness in straight punching process.

at semi-stable austenitic stainless steel such, as SUS304, is different from the common metals. ${ }^{7)}$

$\mathrm{Md}_{30}$ which is the temperature at which $50 \%$ of martensite is formed in tension after a true strain of 0.0 is calculated at $50^{\circ} \mathrm{C}$ from the chemical composition as shown in Table 1 by Angel's formula. ${ }^{8)}$ It is thought that the sample will be easily heated to such temperature by working. By the reason, the behavior of working-hardening is influenced by the atmosphere temperature or the sample temperature, because by the behaviors of formation of martensite are strongly influenced by the experimental temperature.
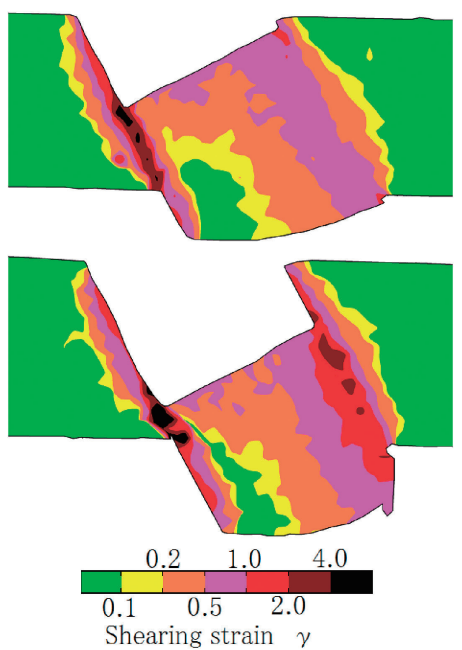

Fig. 9 Map of shearing strain in slanted punching process.
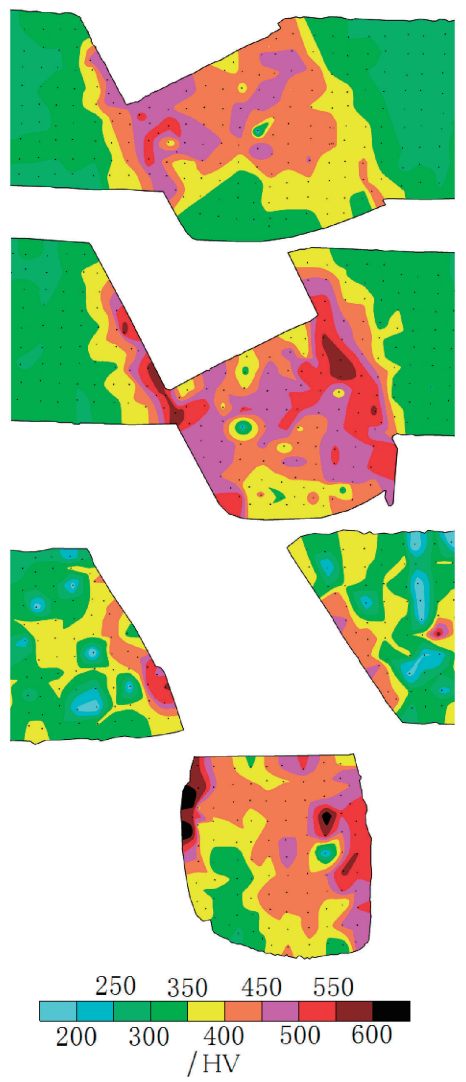

Fig. 10 Map of Vickers hardness in slanted punching process.

In this paper, the experiments of straight punching, done at a previous time, extracted from the experiments of slanted punching at the temperature of samples and the atmosphere was uncontrolled. Then it may be inferred that at the experimental temperatures employed here, the straight and the slanted punching differed from each other. Thus, we discuss the behavior of the worked material only by relative hardness.

There is another problem that $10 \mu \mathrm{m}$ of the measurement distance was not long enough for about $5 \mu \mathrm{m}$ of Vickers indentation. But, it turns out that there was no problem where the indentation size was about 10 times the wavelength of 
light, and the influence of the next indentation was smaller than the measurement error of the indentation size. In addition, if the influence for all measurements of the next indentations were believed to be at a similar level, then the influence becomes inconsequential for discussion of relative hardness.

The behavior is simple at straight punching. The shearing strain concentrates near the shearing line.

On the other hand, the behaviors are not simple at slanted punching. Shearing strain about $30^{\circ}$ was introduced to large part of the punched place at the end of the 1st stage. The hardness of the punched part increased to a larger value at slanted punching as shown in Fig. 10, although a small increase appears at straight punching as shown in Fig. 8. The hardness near the sheared part is extremely-high that is over $600 \mathrm{HV}$ in the locally slanted punched piece. While the austenitic phase remains, the part of austenitic phase, which is softer than martensite, can deform at cold working of the SUS304. But, as it becomes single phase of martensite, the material will be extremely-hardened and will be fractured. ${ }^{9)}$ It is thought that the martensite is formed early at slanted punching. Then it is considered that the similar phenomenon that occurs is caused by the partial deficiency of the austenitic phase. However, the details are unclear in this experiment and are to be addressed in future work.

At the end of the 1st stage and at the end of the 2nd stage, there was a similarity in the strain distribution and hardness distribution as shown in Figs. 9 and 10. It is believed from the fact that the internal strain which is added to the worked material was almost the simple shear directed to the punching direction. But the distribution of hardness spreads through the right and left than the distribution of strain. This suggests that the strain along the plane direction of the sheet which could not be detected from the deformation of the layers structure does exist.

There appeared to be some measurement points that show extremely-low hardness as in Figs. 8 and 10. The low hardness number is not real hardness, but it does suggest the existence of micro voids or the micro fractures under these measurement points. At the presented sheet, 16 points of 1000 points show such extremely-low hardness. Then 2 or 3 points with extremely-low hardness in the figure were derived from the presented sheet, but others were formed in punching process. As shown in Fig. 10, the points which show extremely-low hardness numbers are increased from the end of the 2nd stage to the completion of punching at the slanted punching; and the points are almost placed inside of $45^{\circ}$ line from the sheared surface and from the head of the punched hole. As mentioned before, the linear structures at $45^{\circ}$ to sheared edge are shown from the edges of the inside and outside of the head of the punch. The linear structures are shown barely at the end of the 1st stage and the end of the 2nd stage, by more observations. It is thought that the conically-shaped materials within $45^{\circ}$ from the side of the punch are drawn, and materials before the punch are pushed into the hole of the die at the same time. The straight-line structures which are observed in the photographs of microstructure are thought as the slip plane in the dead metal and the flowing metal. If the structure is a slip plane, it is expected to be the evidence of shearing strain on the line structures.
In fact, measuring points have high hardness values and extremely-low hardness values placed on the straight-line structures. It is considered that the materials on the slip line were work-hardened; and the micro voids or micro-fractures formed at the area where accumulation of the strain reached the limit.

In this experiment, the punch move reliably into the hole of the die despite low lateral stiffness of the punch caused by its thinness, as the diameter of the punch was smaller than the thickness of the worked sheet. The punch was carried by the materials flow.

By the results mentioned above, it is considered that the external forces for punch from the worked materials will change in a complicated way by changes in the material flow, which changes in accord with a gap between the punch, and the die which changes corresponding to the way of punching process. It is considered that the way of the punching process as follows:

\subsection{The 1st stage}

At the punch contact to the surface of the worked sheet, force directed to the outside (right in Fig. 2) occurs for the punch, as similar to the case of with normal size slanted punching, and moment (directed to clockwise rotation in Fig. 2) occurs because by the punch off-center contacts to the worked sheet. In this stage, $30^{\circ}$ of shearing strain (comparable with $44 \%$ rolling) is introduced to the almost of the punched part. Then strain-induced marten sites form at the punched part. Behavior of material in the stage is similar to the case where cutting at first and forging at the next.

\subsection{First half of the 2nd stage}

Flow near around the punch is stable, and the punch moves approximately straight. External force on the punch from the worked material is added to the head of the punch axis direction of the punch.

\subsection{Latter half of the 2 nd stage}

The gap with die, and punch becomes extremely-narrow at the inside (left in Fig. 2), local work-hardening and martensite transformation does occur simultaneously, and then Vickers hardness becomes over $600 \mathrm{HV}$. By this reason, the head of the punch is pushed for outside and moment, which has a fulcrum point at the inside as hardened material and the moment direction is clockwise rotation.

\subsection{The 3rd stage}

The material flow stops at the inside caused by the fracture of the worked sheet; however, the flow remains on the outside. Then the head of the punch is pushed for inside and introduced into the hole of the die. In this stage, the punched piece is only held on the outside by the worked sheet; then moment in a counterclockwise direction does occur, and punched piece rotates a little.

It is considered that the maximum punching load is shown during the time interval of the 2nd stage and 3rd stage, and direction of moment, which is added to the head of the punch will reverse momentarily at the time. It means that extremely hard changing of external force for tools occurs that the moment reverse at maximum load is added to the punch. 
And it is thought that processing quality will be influenced by these behaviors of worked materials and distribution of hardness or strain, but this discussion has to be addressed when dealing with future problems.

\section{Conclusion}

We observed the deformation of worked materials in the slanted punching of a fine hole with $94 \mu \mathrm{m}$ of the diameter at SUS304 sheet with $100 \mu \mathrm{m}$ of thickness. At the early stage of working, the worked material shows the behavior as similar with forging at slanted punching. Then the materials at almost part of punched piece were hardened at slanted punching, although only near the shearing parts were hardened at straight punching. Non-uniform hardening does occur at the way of working, and it is thought that the direction of moment, which is added to the head of the punch, reverses momentarily at the time when a maximum working load is shown. The punch in this experiment has low lateral stiffness, but the punch move reliably into the hole of the die because by material flow, which is directed into the die hole. And hardness is extremely high and it is $600 \mathrm{HV}$ at local area.

\section{REFERENCES}

1) T. Komatsu, M. Komatsu, H. Yanagisawa, T. Uehara, T. Yanagisawa and S. Manabe: J. JSTP 52 (2011) 1281-1285.

2) The Japan Society for Technology of Plasticity: Soseikako Nyumon, (CORONA PUBLISHING Co., ltd., Tokyo, 2007) pp. 73-74.

3) I. Ichikawa, H. Yaginuma and K. Matsuno: Proc. 32th Japanese Joint Conference for the Technology of Plasticity, (1981) pp. 381-384.

4) I. Ichikawa, H. Yaginuma and K. Matsuno: Proc. 1982 Japanese Spring Conference for the Technology of Plasticity, (1982) pp. 471-474.

5) T. Komatsu, H. Kobayashi, S. Torizuka and S. Nagayama: Int. J. Autom. Tech. 6 (2012) 802-806.

6) M. Katoh and Y. Torisaka: Tetsu-to-Hagané 84 (1998) 127-130.

7) I. Tamura: Tetsu-to-Hagané 56 (1970) 429-445.

8) T. Angel: J. Iron Steel Inst. 177 (1954) 165-174.

9) M. Katoh and Y. Torisaka: Tetsu-to-Hagané 89 (2003) 1038-1043. 